Abstracta Iranica Abstracta Iranica

Revue bibliographique pour le domaine irano-aryen

Volume 32-33 | 2013

Comptes rendus des publications de 2009-2010

\title{
Seyed Mohammad Reza Darbandi, Antigoni Zournatzi (eds.). Ancient Greece and Ancient Iran
}

Cross-Cultural Encounters, Athens, $1^{\text {st }}$ International Conference (11-13 november 2006)

\section{Rémy Boucharlat}

\section{(2) OpenEdition}

Journals

Édition électronique

URL : http://journals.openedition.org/abstractairanica/40227

DOI : $10.4000 / a b s t r a c t a i r a n i c a .40227$

ISSN : 1961-960X

Éditeur :

CNRS (UMR 7528 Mondes iraniens et indiens), Éditions de l'IFRI

Édition imprimée

Date de publication : 1 décembre 2013

ISSN : 0240-8910

Référence électronique

Rémy Boucharlat, « Seyed Mohammad Reza Darbandi, Antigoni Zournatzi (eds.). Ancient Greece and Ancient Iran », Abstracta Iranica [En ligne], Volume 32-33 | 2013, document 51, mis en ligne le 01 juillet 2016, consulté le 26 septembre 2020. URL : http://journals.openedition.org/abstractairanica/40227 ; DOI : https://doi.org/10.4000/abstractairanica.40227

Ce document a été généré automatiquement le 26 septembre 2020

Tous droits réservés 


\title{
Seyed Mohammad Reza Darbandi, Antigoni Zournatzi (eds.). Ancient Greece and Ancient Iran
}

Cross-Cultural Encounters, Athens, $1^{\text {st }}$ International Conference (11-13

november 2006)

\author{
Rémy Boucharlat
}

\section{RÉFÉRENCE}

Seyed Mohammad Reza Darbandi, Antigoni Zournatzi (eds.). Ancient Greece and Ancient Iran. Cross-Cultural Encounters, Athens, $1^{\text {st }}$ International Conference (11-13 november 2006). Athens, National Hellenic Research Foundation - Cultural Center of the Embassy of the Islamic Republic of Iran - Hellenic National Commission for UNESCO, 2008, XXIX-377 p., nbses ill.

1 Fruit d'une décision politique de renforcer les relations culturelles entre les deux pays, le colloque de 2006, dont ces Actes rendent compte, réunit 24 contributions, très majoritairement sur la période achéménide, mais également sept sur les périodes postérieures, hellénistique et sassanide. Pour la plupart, elles sont en rapport avec le thème, dans certains cas de manière très générale tandis que dans d'autres papiers, l'autre' est plus prétexte que réel objet de discussion. Ouvrage quelque peu disparate, il sera toutefois utile par la majorité des contributions. Ne sont mentionnés ici que les articles se rapportant à l'époque achéménide et à celle d'Alexandre. On trouvera un compte-rendu de deux articles sur des périodes postérieures (voir c.r. nº 138 et 197).

2 Ch. Tuplin, «The Seleucids and Their Achaemenid Predecessors: A Persian Inheritance? » (p. 109-136) plaide pour le changement d'un empire à l'autre, mais non la rupture en prenant comme exemples, l'administration fiscale, le gouvernement des territoires, la mise en scène de la royauté, la fin du «nomadisme du roi». G. G. Aperghis, « Managing an Empire - Teacher and Pupil» (p. 137-148), au contraire, 
plaide pour un "High degree of continuity in the administration of the two empires", dans la structure administrative, le dons de terres par le roi, mais il est vrai fréquemment aux cités ce qui est nouveau, les dons aux temples, car ce sont aussi des centres économiques. La taxation en monnaie ne serait que le changement de support qui était en nature (ou métal) sous les Achéménides.

D. Stronach, «The Building Program of Cyrus the Great at Pasargades and the Date of the Fall of Sardis » (p. 149-173) offre sa vision actuelle des monuments qu'il a largement contribué à faire connaître. Il tient, avec raison, qu'il était impossible d'entreprendre l'une ou l'autre de ces constructions sans le concours des artisans lydo-ioniens. Pour la date de la prise de Sardes, il propose 545 au lieu de 547 comme le pensent certains, surtout en se fondant sur des études récentes d'historiens. M.H. Talebian, «Persis and Greece: The Rôle of Cultural Interactions in the Architecture of Persepolis-Pasargadae » (p. 175-193) fait d'abord une critique trop facile des devanciers, mettant en cause des choix faits dans le passé par des spécialistes occidentaux qui auraient eu une fausse vision des vestiges et de leur histoire. L'A. oublie des décisions purement iraniennes, comme l'aménagement de Persépolis pour les fêtes du $2500^{\mathrm{e}}$ anniversaire, ou l'enlèvement des colonnes autour du tombeau de Cyrus, mises là à l'époque médiévale ; il est vrai que ce sont des éléments de l'histoire du monument, dont l'UNESCO recommande le maintien. Le reste de l'article plaide, avec raison, pour l'approche d'un site dans sa globalité, mais pour cela l'A. interprète trop rapidement une série de recherches récentes. M. C. Root, "Reading Persepolis in Greek - Part Two: Marriage Metaphors and Unmanly Virtues » (p. 195-221) fait suite à son «Reading Persepolis in Greek: gifts of the Yauna " (in : M. C. Tuplin, ed., Persian Response: Political and Cultural Interaction with(in) the Achaemenid Empire, 2007; cf. Abs. Ir. 30, c.r. n 96). Un Grec éduqué (fictif) devant les reliefs de Persépolis vers 460 serait moins surpris qu'on le pense souvent, capable de replacer ces images (non narratives) dans un contexte culturel différent du sien. Ces images ont une fonction, mais ne représentent pas toute la diversité des thèmes qu'ont produite les Achéménides, comme en témoignent les sceaux, entre autres.

4 Y. Lintz, «Greek, Anatolian, and Persian Iconography in Asia Minor: Material Sources, Method, and Perspectives» (p. 257-263) présente brièvement son étude en cours, un corpus des objets achéménides en Asie Mineure occidentale. Achéménide est difficile à définir ; la provenance ou bien le commanditaire, s'il est identifiable, peuvent y aider, mais en cas de doute l'A. privilégie le choix large plutôt que restrictif. Une entreprise d'envergure mais nécessaire. L. Summerer, «Imaging a Tomb Chamber: The Iconographic Program of the Tatarl Wall paintings» (p. 265-299) donne une étude préliminaire du décor peint d'une tombe construite sous tumulus, près de Kelainai ; elle est datée du milieu du $\mathrm{V}^{\mathrm{e}} \mathrm{s}$. av. J.-C. Pillée en 1969, et peu après fouillée en urgence, la tombe est aujourd'hui l'objet d'études détaillées (voir L. Summerer, A . von Kienlin, Tatarl. The Return of Colours / Renklerin Donusu / Ruckkehr der Farben, Istanbul, 2010). S. A. Paspalas, "The Achaemenid Lion-Griffin on a Macedonian Tomb Painting and on a Sicyonian Mosaic» (p. 301-325). La conquête d'Alexandre ne marque pas la fin de la diffusion de motifs achéménides, bien au contraire, comme le montre le décor d'une tombe macédonienne datée de la fin du IV e siècle. A. Sideris, "Achaemenid Toreutics in the Greek Periphery » (p. 339-366) tente une classification de ces objets, achéménides ou achéménidisants - il est souvent difficile d'en décider - en étudiant le contexte de production et la circulation. Sachant que ce type de documents a rarement été trouvé 
en fouilles régulières, la reconnaissance des ateliers que propose l'A. ne peut se fonder que sur la technique et le style.

\section{AUTEURS}

\section{RÉMY BOUCHARLAT}

CNRS, Lyon 